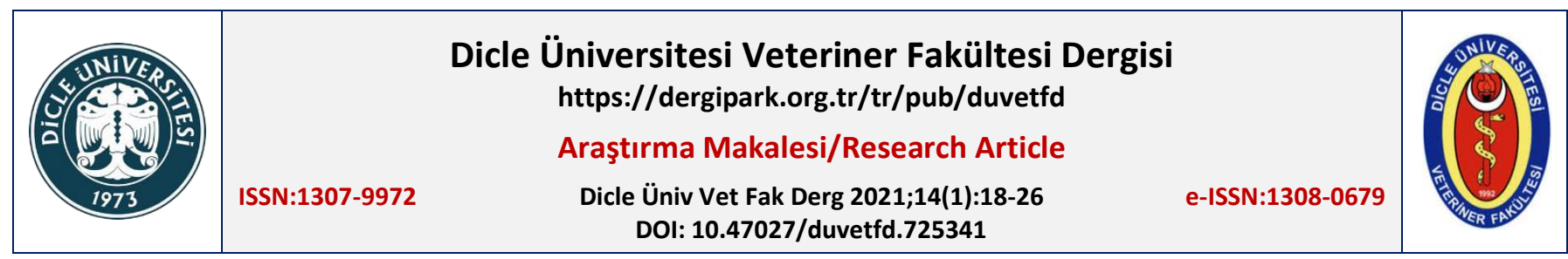

\title{
Diyarbakır Yöresinde Hayvan Hastalıkları ve Yetiştiriciliğinde Kullanılan Bitkiler
}

\author{
Rahşan ÖZEN ${ }^{1, a, \otimes}$ \\ ${ }^{1}$ Fırat Üniversitesi Veteriner Fakültesi, VHT ve Deontoloji Anabilim Dalı, Elazı̆̆, TÜRKiYE \\ aORCID: 0000-0001-5788-0289
}

\begin{tabular}{ccc}
\hline Geliş Tarihi/Received & Kabul Tarihi/Accepted & Yayın Tarihi/Published \\
15.01 .2021 & 12.03 .2021 & 30.06 .2021 \\
\hline
\end{tabular}

Öz

Bu çalışma ile Diyarbakır yöresinde halk arasında hayvan hastalıkları ve yetiştiriciliğinde kullanılmakta olan bitkilere ilişkin bilgilerin tespiti amaçlandı. Bu amaçla Ocak 2017- Aralık 2018 tarihleri arasında Diyarbakır Merkez ve hayvancılığın yoğun yapıldığı yerleşim yerlerinde 82 kişi ile görüşülerek saha çalışması tamamlandı. Çalışmalar sonucunda yörede hayvan hastalık ve yetiştiriciliğinde 43 familyaya ait toplam 75 bitkinin kullanıldı̆ı saptandı. En yaygın kullanılan bitkilerin Rosaceae, (8 bitki), Asteraceae (7 bitki) ve Solanaceae (4 bitki) ailelerine ait olduğu belirlendi. Bu bitkilerin, hayvanlarda kırık, yaralar, apse, şişkinlik, zehirlenme, güç doğum, eşin düşmemesi, iç, dış ve kan parazit mücadelesi, sarılık, öksürük, sancı, kabızlık, yanık, vitamin eksikliği, arı sokması ve ishal durumları, göz, kalp, meme hastalıkları ve şap hastalığının tedavisinde kullanıldı̆̆ belirlendi. Bitkilerin toprak üstü kısımlarının, meyvelerinin, yapraklarının, tohumlarının, yağının, sakızının, kökünün, çiçeğinin kullanıldığı saptandı. Ayrıca yörede, hayvan yetiştiriciliğinde iştah, süt, et, yumurta, döl verimi artırıcı olarak; ses güzelleştirici ve bağışıklık sistemini güçlendirmek amaçlı bitkilerden faydalanıldığı belirlendi. Sonuç olarak, Diyarbakır yöresinde yapılan bu çalışma ile bitkilerin, hayvan hastalık ve yetiştiriciliğinde kullanım amaç, yöntem ve şekillerinin kayıt altına alınmasının, hem kültürel mirasın korunması hem de yeni ilaç araştırmalarına kaynak oluşturabilme potansiyeli açısından önem taşıdığı söylenebilir.

Anahtar Kelimeler: Bitkiler, Diyarbakır, veteriner hekimliği folkloru

Animal Diseases and Breeding Used Plants in Diyarbakır Region

\section{Abstract}

In this study, it was aimed to determine the information about the plants used in animal diseases and animal breeding in Diya rbakır region. For this purpose a survey conducted on 82 people between January 2017 and December 2018 in Diyarbakır city center and animal husbandry settlements. As a result of the studies, a total of 75 plants belonging to 43 families were used in animal diseases and animal breeding in the region. The most commonly used families were Rosaceae (8 plants), Asteraceae ( 7 plants) and Solanaceae (4 plants). These plants are fractures in animals, wounds, abscesses, tympanites, intoxication, dystocia, placental retention, endoparasitic, ectoparasitic and blood parasitic infections, jaundice, cough, pain, constipation, burn, vitamin deficiency, bee sting and diarrhea cases, treatment of eye, heart, udder diseases and foot-and-mouth disease; above-ground parts, fruits, leaves, seeds, oil, chewing gum, root, flower were found to be used. In addition it was determined that appetizer, milk, meat, eggs, soe plants which are used for increasing fertility, voice enhancement and strengthen the immune system were used in animal breeding in the region. As a result of this study conducted in Diyarbakır region, it can be said that recording the using purpose, method and forms of the plants in animal diseases and breeding is important both for protecting cultural heritage and for the potential of generating a resource for new drug researches.

Key Words: Plants, Diyarbakır, Veterinary folklore

\section{GiRiş}

Tarihin en eski dönemlerinden beri insanoğlunun hem kendi hem de hayvanlarının hastalıklarının tedavisinde ilk başvurduğu kaynak şüphesiz bitkilerdir (1,2). Binyıllardan beri çeşitli toplumlarda tedavi edici olarak kullanılan bazı bitkiler, günümüzde de ilaçlara oranla daha düşük maliyetli oldukları ve kolay uygulanabilirlikleri nedeniyle özellikle ekonomik durumu iyi olmayan hayvan yetiştiricileri tarafından hem Dünya'da hem de Türkiye' de hala tercih edilmekte ve kullanılmaktadır $(3,4)$.

Hiç şüphesiz, Anadolu'nun bereketli toprakları, bitki çeşitliliği açısından dünyanın en zengin coğrafyalarından biridir
(5). Bugüne kadar bu coğrafyada yaklaşık 12.000 bitki türü belirlenmiş; bunların yaklaşık üçte birinin Güneydoğu Anadolu Bölgesinde bulunduğu saptanmıştır $(6,7)$. Dünyada, insanlığın yerleşik hayata geçtiği ve tarımın yapıldığı ilk yer olarak kabul edilen Güneydoğu Anadolu Bölgesinin sosyal ve geleneksel yapısı, bölge genelinde yüzlerce yıldan beri sürdürülen folklorik uygulama ve tedavi yöntemlerinin önemli bir kısmının değişmeden günümüze dek gelebilmesine yol açmıştır $(8,9)$. Bu durum Güneydoğu Anadolu Bölgesinde yer alan illerde gerek tıbbi gerekse veteriner hekimliği folkloru açısından zengin bir birikimin oluşmasına da imkân sağlamıştır $(9,10)$. 
Bu çalışma ile Diyarbakır yöresinde halk arasında geçmişten günümüze hayvan hastalıkları ve yetiştiriciliğinde kullanılan bitkilerin belirlenmesi, bu bitkilerin kullanımlarına ilişkin bilgilerin tespiti ve kaybolmaya yüz tutmuş bilgilerin kayıt altına alınarak gelecek kuşaklara aktarılması amaçlanmıştır.

\section{MATERYAL VE METOT}

Araştırma alanı, Güneydoğu Anadolu'da yer alan İran-Turan floristik bölgesi ile temsil edilen ve P.H. Davis'in (11) Türkiye Haritası Kareleme (Grid) Sistemi'ne göre, B7-B8-C7-C8 karelerinde bulunan Diyarbakır ilidir (Şekil 1). Çalışmanın materyali, Ocak 2017- Aralık 2018 tarihleri arasında Diyarbakır ve yöresinde hayvancılığın yoğun olarak yapıldığı yerleşim birimlerinden toplam 82 kaynak kişi ile yapılan görüşmelerden elde edilen verilerden sağlandı (Tablo 1). Bulgularda yer alan Türkçe ve Kürtçe bitki adları kaynak kişilerin beyanları esas alınarak yazıldı. Latince ve tür adlarının yazımında "Türkçe Bitki Adları Sözlüğü" (12) ve "Kürtçe Bitki Adları Sözlüğü"nden (13) faydalanıldı. Araştırmada sosyal bilimlerde nitel araştırma yöntemlerinden birisi olan "kaynak kişilerle görüşme tekniği” kullanıldı. Görüşmelerle, gönüllü kaynak kişilere çalışma hakkında bilgi verilerek ve izinleri alınarak bilgi derleme formu yoluyla yazılı ve görsel veriler toplandı. Elde edilen verilerin değerlendirilmesi hem SPSS 20 paket programı yardımı ile hem de içerik analizi kullanılarak yapıldı.

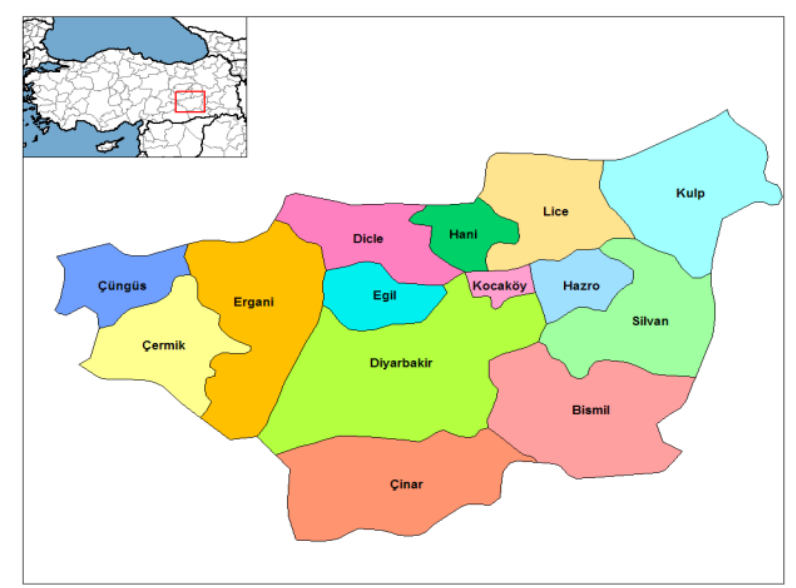

Şekil 1. Araştırma alanı - Diyarbakır

Tablo 1. Kaynak Kişi Listesi

\begin{tabular}{|c|c|c|c|c|c|}
\hline $\begin{array}{l}\text { KK } \\
\text { No } \\
\end{array}$ & Adı Soyadı & Eğitim Durumu & Mesleği & Yaşı & Yaşadığı Yer \\
\hline 1 & Abdullah Çallı & illkokul & Çiftçi & 42 & Kocaköy \\
\hline 2 & Hamdullah Çallı & İlkokul & Çiftçi & 42 & Kocaköy \\
\hline 3 & Tahsin Mutlu & İlkokul & Çiftçi & 56 & Esenler -Lice \\
\hline 4 & Mehmet Zaid Tarhan & İlkokul & Çiftçi & 60 & Yazıköyü-Kocaköy \\
\hline 5 & Mustafa Kaya & İlkokul & Çiftçi & 33 & Kocaköy \\
\hline 6 & Mehmet Öztürk & İlkokul & Çiftçi & 46 & Kocaköy \\
\hline 7 & Mehmet Yıldız & İlkokul & İşçi & 42 & Köklüpınar-Kocaköy \\
\hline 8 & Fatih Alkın & Ortaokul & Esnaf & 22 & Kocaköy \\
\hline 9 & Naci Kaya & İlkokul & Çiftçi & 45 & Kocaköy \\
\hline 10 & Mehmet Kaya & Ortaokul & Çiftçi & 26 & Kocaköy \\
\hline 11 & Hüseyin Yıldız & İlkokul & Muhtar & 43 & Köklüpınar-Kocaköy \\
\hline 12 & Şerif Turan & Üniversite & Veteriner hekim & 26 & Çınar \\
\hline 13 & Ahmet İhsan Önal & illkokul & Hayvan yetiştiricisi & 52 & Çermik \\
\hline 14 & Süleyman Araç & Lise & Hayvan yetiştiricisi & 30 & Hazro \\
\hline 15 & Mehmet Çiçek & Ortaokul & Hayvan yetiştiricisi & 31 & Kulp \\
\hline 16 & Hüseyin Yılmaz & Lise & Hayvan yetiştiricisi & 53 & Merkez-Diyarbakır \\
\hline 17 & Necdet Özaydın & Üniversite & Öğretmen & 36 & Bismil \\
\hline 18 & Vahide Yiğit & Okur-yazar değil & Hayvan yetiştiricisi & 56 & Cömert- Ergani \\
\hline 19 & Ferhan Polat & İlkokul & Hayvan yetiştiricisi & 48 & Örenkuyu-Çermik \\
\hline 20 & Reşat Karacadağ & İlkokul & Hayvan yetiştiricisi & 52 & Ziyaret- Bağlar \\
\hline 21 & Hüseyin Polat & Lise & Hayvan yetiştiricisi & 61 & Yeniköy \\
\hline 22 & Seydo Çiftçi & İlkokul & Hayvan yetiştiricisi & 47 & Örenkuyu-Çermik \\
\hline 23 & İsmail Karacadağ & İlkokul & Hayvan yetiştiricisi & 45 & Ziyaret- Bağlar \\
\hline 24 & Fesih Dursun & İlkokul & Hayvan yetiştiricisi & 43 & Kulp \\
\hline 25 & Yahya Anda & İlkokul & Hayvan yetiştiricisi & 43 & Ecemiş-Lice \\
\hline 26 & Mustafa Aksu & İlkokul & Hayvan yetiştiricisi & 54 & Lice \\
\hline 27 & Şahin Tezer & İlkokul & Çiftçi & 36 & Ergani \\
\hline 28 & Naciye Mete & Okur-yazar & Hayvan yetiştiricisi & 48 & Sağlıca-Ergani \\
\hline 29 & Remzi Coşkun & Üniversite & Çiftçi & 25 & Yamaçlar-Ergani \\
\hline 30 & Kadir Kaygusuz & Üniversite & Çiftçi & 27 & Ergani \\
\hline 31 & Askeri İpek & İlkokul & Hayvan yetiştiricisi & 33 & Tuntepe-Ergani \\
\hline
\end{tabular}




\begin{tabular}{|c|c|c|c|c|c|}
\hline \multicolumn{6}{|c|}{ TABLO1'ÍN DEVAMI } \\
\hline $\begin{array}{l}\text { KK } \\
\text { No }\end{array}$ & Adı Soyadı & Eğitim Durumu & Mesleği & Yaşı & Yaşadığı Yer \\
\hline 32 & Şaban Yalçınkaya & illkokul & Hayvan yetiştiricisi & 45 & Yenişehir \\
\hline 33 & Sedat Yakut & İlkokul & Hayvan yetiştiricisi & 42 & Çamlıköy-Dicle \\
\hline 34 & Servet İşgören & İlkokul & Çiftçi & 48 & Pınarkaya-Ergani \\
\hline 35 & Faysal Zengin & Lise & Hayvan yetiştiricisi & 51 & Elmedin-Ergani \\
\hline 36 & Süleyman Ulu & Okur-yazar & Hayvan yetiştiricisi & 69 & Kabasakal-Ergani \\
\hline 37 & Aziz Polat & Üniversite & Veteriner hekim & 52 & Merkez-Diyarbakır \\
\hline 38 & Celal Arat & Ortaokul & Hayvan yetiştiricisi & 51 & Ziyaret-Bağlar \\
\hline 39 & Yunus Çelik & Üniversite & Veteriner hekim & 28 & Ergani \\
\hline 40 & Fesih Menekşe & illkokul & Hayvan yetiştiricisi & 39 & Çınar \\
\hline 41 & Mehmet Pekdoğan & Üniversite & Serbest & 24 & Hani \\
\hline 42 & Örfi Pekdoğan & İlkokul & Hayvan yetiştiricisi & 47 & Hani \\
\hline 43 & Bedirhan Üstün & Üniversite & Veteriner hekim & 58 & Merkez-Diyarbakır \\
\hline 44 & Abdullah Umay & İlkokul & Hayvan yetiştiricisi & 63 & Yukarı eğin \\
\hline 45 & Sıddık Erdoğan & İlkokul & Hayvan yetiştiricisi & 63 & Hani \\
\hline 46 & Fatma Pekdoğan & Okur-yazar değil & Hayvan yetiştiricisi & 49 & Hani \\
\hline 47 & M. Hanifi Yalçınkaya & İlkokul & Hayvan yetiştiricisi & 44 & Kaldırım-Kayapınar \\
\hline 48 & Mehmet Şahin & İlkokul & Hayvan yetiştiricisi & 64 & Merkez-Diyarbakır \\
\hline 49 & Mehmet Pekdoğan & Okur-yazar değil & Hayvan yetiştiricisi & 63 & Goma-Hani \\
\hline 50 & Yaşar Pekdoğan & Okur-yazar & Hayvan yetiştiricisi & 53 & Hani \\
\hline 51 & Bahri Menekşe & Okur-yazar & Hayvan yetiştiricisi & 53 & Çınar \\
\hline 52 & Hacı Tevfik Çeker & illkokul & Hayvan yetiştiricisi & 53 & Alatosun-Bağlar \\
\hline 53 & Sefer Yorulmaz & Okur-yazar değil & Serbest & 58 & Akçoban-Ergani \\
\hline 54 & Hasan Yorulmaz & Okur-yazar & Çiftçi & 52 & Akçoban-Ergani \\
\hline 55 & Havva Yorulmaz & Okur-yazar değil & Ev hanımı & 38 & Akçoban-Ergani \\
\hline 56 & Hasan Akdemir & Okur-yazar değil & Hayvan yetiştiricisi & 67 & Çardaklı-Hani \\
\hline 57 & Mehmet Ali Yılmaz & Okur-yazar & Çiftçi & 50 & Merkez-Diyarbakır \\
\hline 58 & Enuş Tokcan & Okur-yazar & Çiftçi & 38 & Merkez-Diyarbakır \\
\hline 59 & M. Emin Çeliker & İlkokul & Serbest & 35 & Gürbüz-Hani \\
\hline 60 & Abdulvahap Eroğlu & İlkokul & Hayvan yetiştiricisi & 49 & Salman -Ergani \\
\hline 61 & Adil Dağ & İlkokul & Serbest & 24 & Karasüngü-Çınar \\
\hline 62 & Ömer Güven & Okur-yazar değil & Hayvan yetiştiricisi & 64 & Cumhuriyet- Kayapınar \\
\hline 63 & İbrahim Yılmaz & İlkokul & Hayvan yetiştiricisi & 53 & Yolboyu-Diyarbakır \\
\hline 64 & İzzettin Deviren & İlkokul & Çiftçi & 53 & Pirinçlik-Kayapınar \\
\hline 65 & Reşit Ağaç & İlkokul & Hayvan yetiştiricisi & 47 & Pirinçlik-Kayapınar \\
\hline 66 & Mehmet Koyun & Okur-yazar değil & Hayvan yetiştiricisi & 91 & Silvan \\
\hline 67 & Ramazan Salık & Lise & Çiftçi & 24 & Kocaköy \\
\hline 68 & Mustafa Yaman & Okur-yazar & Hayvan yetiştiricisi & 47 & Alitaş-Ergani \\
\hline 69 & Yakup Canpolat & Üniversite & Mali müşavir & 43 & Merkez-Diyarbakır \\
\hline 70 & Sıddık İz & Okur-yazar & Hayvan yetiştiricisi & 53 & Boytarca-Kayapınar \\
\hline 71 & Mustafa Kaya & Okur-yazar & Hayvan yetiştiricisi & 53 & Ekinci-Bağlar \\
\hline 72 & Ömer Turan & İlkokul & Çiftçi & 41 & Çermik \\
\hline 73 & Ömer Aktaş & Okur-yazar & Çiftçi & 48 & Gürakar-Diyarbakır \\
\hline 74 & Rıfat Yavuzer & İlkokul & Hayvan yetiştiricisi & 34 & Kamışpınar-Bağlar \\
\hline 75 & Halit Koçyiğit & Üniversite & Mimar & 53 & Merkez-Diyarbakır \\
\hline 76 & Şirin Çelik & Üniversite & Ziraatçı & 29 & Merkez-Diyarbakır \\
\hline 77 & Suat Hocaoğlu & Üniversite & Veteriner hekim & 35 & Merkez-Diyarbakır \\
\hline 78 & Sabri Aygün & Yüksekokul & Sağlık memuru & 57 & Merkez-Diyarbakır \\
\hline 79 & Fatih Can & Üniversite & Serbest & 33 & Gözekaya-Ergani \\
\hline 80 & Metin Polat & Ortaokul & Çoban & 28 & Sağlıca-Ergani \\
\hline 81 & Abdullatif Yıldırım & İlkokul & Çiftçi & 50 & Sılsülü-Hani \\
\hline 82 & İlhan Yazıcı & Ortaokul & Hayvan yetiştiricisi & 54 & Lice \\
\hline
\end{tabular}

\section{BULGULAR}

Katılımcıların \%5'i ( $n=4)$ kadın, \%95'i ( $n=78)$ erkektir. Ankete katılanların \%23'ünün ( $n=19)$ 46-52 yaş aralığında yer aldığı görülmektedir. Eğitim durumlarına bakıldığında; büyük çoğunluğun (\%55), (n=39) ilkokul mezunu olduğu anlaşılmaktadır.

Diyarbakır ve yöresinde hayvan hastalıkları ve yetiştiriciliğinde kullanılan 43 familyaya ait toplam 75 bitkinin kullanıldığı saptandı. En yaygın olarak kullanılan bitkilerin Rosaceae, ( 8 bitki), Asteraceae (7 bitki) ve Solanaceae (4 bitki) ailelerine ait olduğu belirlendi. Bu bitkilerin bilimsel adları, yöresel adları, familyaları, kullanılan kısımları ve kullanım şekilleri Tablo 2'de verilmiştir. 
Tablo 2. Diyarbakır ve Yöresinde Hayvan Hastalıkları ve Yetiştiriciliğinde Kullanılan Bitkiler

\begin{tabular}{|c|c|c|c|c|c|}
\hline Familya & Latince tür & Yöresel ad & Kullanılan kısım & Kullanma şekli & Kullanım amacı \\
\hline Alliaceae & Allium porrum & Pırasa & $\begin{array}{l}\text { Toprak üstü kısım- } \\
\text { ları }\end{array}$ & Yedirilir. & İştahsızlık (KK 39) \\
\hline $\begin{array}{l}\text { Amarantha- } \\
\text { ceae }\end{array}$ & Amaranthus sp. & “Köksor" & $\begin{array}{l}\text { Toprak üstü kısım- } \\
\text { ları }\end{array}$ & Kaynatılıp suyu içirilir. & İshal (KK 35) \\
\hline \multirow[t]{2}{*}{ Anacardiaceae } & Rhus sp. & $\begin{array}{l}\text { "Sımak" } \\
\text { Sumak }\end{array}$ & $\begin{array}{l}\text { Meyveleri } \\
\text { Salkım } \\
\text { Kitre }\end{array}$ & $\begin{array}{l}\text { Meyveleri veya salkım halinde } \\
\text { kaynatılır. } \\
\text { Taze şekilde ezilir ya da yedirilir. }\end{array}$ & $\begin{array}{l}\text { "Tebek" Şap hastalığı (KK1,3,12,13,14,27,28,30,32, } \\
\text { 34,35,36,39,41,47,49,51,58,62,65,66,68,70,71) } \\
\text { Yaralar (KK 13, 23-25) İshal (KK28, } \\
\text { KK31,33,34,36,64,67,80). Sülük (KK 78), Gingivitis (KK } \\
\text { 18), Dil oynatma hastalığı (KK 39) Bağışıklık sistemini } \\
\text { güçlendirici (KK 69), Kuzularda antipiretik (KK 69) }\end{array}$ \\
\hline & $\begin{array}{l}\text { Pistacia } \\
\text { terebinthus }\end{array}$ & $\begin{array}{l}\text { Sakız ağacı } \\
\text { Menengiç }\end{array}$ & Sakızı & $\begin{array}{l}\text { Un haline getirilerek yaraya veya } \\
\text { kırığa sarılır. }\end{array}$ & Yaralar (KK 78), Kırık (KK 78) \\
\hline Araceae & Arum sp. & $\begin{array}{l}\text { "Kari" } \\
\text { "Kardi" }\end{array}$ & Kökü & $\begin{array}{l}\text { Ezilerek veya haşlanıp yaraya sarı- } \\
\text { lır. Mazı dövülüp tozu ve kenger } \\
\text { sapı ve yaprağın külü ile karıştııııı. }\end{array}$ & Yaralar (KK 45,72,78) \\
\hline \multirow{7}{*}{ Asteraceae } & $\begin{array}{l}\text { Gundelia tourne- } \\
\text { fortii }\end{array}$ & $\begin{array}{l}\text { "Kereng" } \\
\text { Kenger }\end{array}$ & $\begin{array}{l}\text { Toprak üstü kısım- } \\
\text { ları }\end{array}$ & $\begin{array}{l}\text { Kaynatılır suyu sürülür } \\
\text { Ezilerek uygulanır. }\end{array}$ & $\begin{array}{l}\text { Yaralar (KK 4),Uyuz (KK78) } \\
\text { Mantar (KK 78) }\end{array}$ \\
\hline & $\begin{array}{l}\text { Chrysophthal- } \\
\text { mum montanum }\end{array}$ & "Sımmo" & $\begin{array}{l}\text { Toprak üstü kısım- } \\
\text { ları }\end{array}$ & Kaynatılır suyu sürülür. & Yaralar (KK 61) \\
\hline & Anthemis sp. & $\begin{array}{l}\text { Papatya } \\
\text { "Kululik" } \\
\text { "Gihaye çiçeki } \\
\text { cenini cinneti" }\end{array}$ & $\begin{array}{l}\text { Toprak üstü kısım- } \\
\text { ları, çiçekler }\end{array}$ & $\begin{array}{l}\text { Kaynatılıp suyu içirilir. } \\
\text { Çiçekler kaynatılıp suyu içirilir. }\end{array}$ & $\begin{array}{l}\text { İshal (KK 15,28,46,79) } \\
\text { Öksürük (KK 6) } \\
\text { Anüri (KK 80) }\end{array}$ \\
\hline & Xanthium sp. & $\begin{array}{l}\text { "Gernık" } \\
\text { "Gurnık" “ }\end{array}$ & $\begin{array}{l}\text { Toprak üstü kısım- } \\
\text { ları }\end{array}$ & Kaynatılır suyu içirilir. & Sancı giderici (KK 80) \\
\hline & Onopordum sp. & "Halundor" & $\begin{array}{l}\text { Toprak üstü kısım- } \\
\text { ları }\end{array}$ & Yedirilir. & İç parazit (KK78) \\
\hline & $\begin{array}{l}\text { Scorzonera latifo- } \\
\text { lia }\end{array}$ & "Nerbendık" & $\begin{array}{l}\text { Toprak üstü kısım- } \\
\text { ları }\end{array}$ & Kaynatılır suyu içirilir. & Güç doğum, Sancı (KK 79) \\
\hline & Lactuca serriola & $\begin{array}{l}\text { Keklik otu, } \\
\text { "Tali" }\end{array}$ & $\begin{array}{l}\text { Toprak üstü kısım- } \\
\text { ları }\end{array}$ & Yedirilir. & Kekliklerde ses güzelleştirici (KK78) \\
\hline Boraginaceae & Anchusa azurea & $\begin{array}{l}\text { “Gürüz" } \\
\text { "Gurüz" } \\
\text { "Geriz" } \\
\text { "Törtün" }\end{array}$ & $\begin{array}{l}\text { Yapraklar } \\
\text { Kök }\end{array}$ & $\begin{array}{l}\text { Yapraklar sarılır. } \\
\text { Kaynatılıp suyu içirilir. } \\
\text { Yedirilir. } \\
\text { Tereyağında kavrulup, yedirilir. } \\
\text { Kaynatılır, su göze sürülür. }\end{array}$ & $\begin{array}{l}\text { Kurtlu yaralar (KK 60,66,78) Apse (KK 41,45) Sancı gide- } \\
\text { rici (KK68,74,78), Tuz zehirlenmesi (KK 74), Ketozis } \\
\text { (KK55), Yılan sokması (KK 56) } \\
\text { Güç doğum / Eşin düşmemesinde (KK13) } \\
\text { Göz hastalıkları (KK13) }\end{array}$ \\
\hline Brassicaceae & $\begin{array}{l}\text { Brassica olera- } \\
\text { ceae }\end{array}$ & Lahana & Yapraklar & Yapraklar apseye sarılır. & Apse (KK 81) \\
\hline Cannabaceae & Cannabis sativa & Kenevir & Tohumu & Yedirilir. & Kanatılıarda döl verimi artırıcı (KK 76) \\
\hline Compositae & Helianthus sp. & Ayçiçeği & Yağı & İçirilir. & Şişkinlik (KK 60, 65, 80), Kabızlık (KK 12,40,63,70) \\
\hline \multirow{3}{*}{ Cucurbitaceae } & Cucurbita mixta & Kış kabağı & Meyveleri & $\begin{array}{l}\text { Gres yağı ile karıştırılarak mer- } \\
\text { hem yapılır. }\end{array}$ & İrinli yaralar (KK 73) \\
\hline & Cucumis melo & Kavun & Kabuklar & $\begin{array}{l}\text { Kavun kabuğu veya kavun yediri- } \\
\text { lir. }\end{array}$ & Şişkinlik (KK31), Kabızlık (KK 31) \\
\hline & Citrullus lanatus & Karpuz & Kabuklar & Karpuz kabuğu yedirilir. & Şişkinlik (KK31), Abomasum deplasmanı $($ KK27,29) \\
\hline Cupressaceae & $\begin{array}{l}\text { Juniperus oxyced- } \\
\text { rus }\end{array}$ & Ardıç & Katranı & Sürülür. & Yaralar (KK 48) \\
\hline Cuscutaceae & Cuscuta sp. & $\begin{array}{l}\text { Bostan bozan, } \\
\text { "Dargaring" }\end{array}$ & $\begin{array}{l}\text { Toprak üstü kısım- } \\
\text { ları }\end{array}$ & Kurutulup tuzla yedirilir. & Döl verimi artırıcı (KK 13), Süt artırıcı (KK 78) \\
\hline Euphorbiaceae & Euphorbia sp. & $\begin{array}{l}\text { "Haşul" Sütle- } \\
\text { ğen }\end{array}$ & $\begin{array}{l}\text { Toprak üstü kısım- } \\
\text { ları }\end{array}$ & $\begin{array}{l}\text { Ahıra asılır. Suyla karıştırılıp ka- } \\
\text { bız hayvana içirilir. }\end{array}$ & Dış parazit (KK52), Kabızlık (KK35,36) \\
\hline \multirow{3}{*}{ Fabaceae } & Vicia sp. & $\begin{array}{l}\text { "Kızın" “Mijil” } \\
\text { "Fit" Fiğ }\end{array}$ & $\begin{array}{l}\text { Toprak üstü kısım- } \\
\text { ları }\end{array}$ & Kaynatılır suyu içirilir. Yedirilir. & $\begin{array}{l}\text { Eşin düşmemesinde (KK42, 50) } \\
\text { Süt artırıcı (KK 41) } \\
\text { Kuzularda et verimi artırıcı (KK 42,78) }\end{array}$ \\
\hline & $\begin{array}{l}\text { Cassia angustifo- } \\
\text { lia }\end{array}$ & Sinameki & Yapraklar & Kaynatılır suyu içirilir. & Kabızlık (KK77) \\
\hline & $\begin{array}{l}\text { Trifolium leucant- } \\
\text { hum }\end{array}$ & "Nefel" & $\begin{array}{l}\text { Toprak üstü kısım- } \\
\text { ları }\end{array}$ & Yedirilir. & Süt artırıcı (KK 78), Et verimi artırıcı (KK 78) \\
\hline Fagaceae & Quercus sp. & $\begin{array}{l}\text { Meşe } \\
\text { Palamut } \\
\text { Mazı } \\
\text { "Kerçik" } \\
\text { "Şakalor" (gal) }\end{array}$ & $\begin{array}{l}\text { Meyveleri, } \\
\text { kabuğu, yapraklar, } \\
\text { külü }\end{array}$ & $\begin{array}{l}\text { Kurutulup, toz haline getirilir, } \\
\text { ağacın kabuğunun külü. } \\
\text { Palamut kadehi üzerindeki tüylü } \\
\text { yapı (kerçik) ezilip yaraya uygu- } \\
\text { lanır. "Şakalor" ve "Kerçik" dö- } \\
\text { vülüp un haline getirilir. } \\
\text { Apsede yaprak sarılır. } \\
\text { Palamut kurutulup dövülür, } \\
\text { suyla karıştırılıp içirilir. } \\
\text { Meşe yaprağı yedirilir. } \\
\text { Toz haline getirilip, suyla karıştırılır, } \\
\text { bit ve kene olan yere sürülür. }\end{array}$ & $\begin{array}{l}\text { Yaralar (KK 41,53,63,78) } \\
\text { Kurtlu yara (KK78) } \\
\text { Apse (15) Uyuz (KK78) } \\
\text { İshal (KK41,43,56,64) } \\
\text { Dış parazit (KK 8) } \\
\text { Sülük (KK 78) } \\
\text { Hindilerde et verimi artırıcı (KK 78) }\end{array}$ \\
\hline
\end{tabular}




\begin{tabular}{|c|c|c|c|c|c|}
\hline Familya & Latince tür & Yöresel ad & Kullanılan kısım & Kullanma şekli & Kullanım amacı \\
\hline Hypericaceae & Hypericum sp. & $\begin{array}{l}\text { "Batov" "Ba- } \\
\text { tof" "Batufk" } \\
\text { "Bahtof" } \\
\text { Kantaron }\end{array}$ & $\begin{array}{l}\text { Toprak üstü ve altı } \\
\text { kısımları }\end{array}$ & $\begin{array}{l}\text { Kaynatılıp suyu içirilir } \\
\text { Kaynatılıp suyu bölgeye sürü- } \\
\text { lür. }\end{array}$ & $\begin{array}{l}\text { Şişkinlik (KK17) Sarılık (KK 1,3,26) } \\
\text { Uyuz (KK6), Mantar (KK42,50) } \\
\text { "Zerik, Zerika Reş" Theileria (KK7) }\end{array}$ \\
\hline Juglandaceae & Juglans sp. & Ceviz & $\begin{array}{l}\text { Yapraklar. } \\
\text { İç kısım }\end{array}$ & $\begin{array}{l}\text { Yaprak kurutulur, toz haline } \\
\text { getirilir ya da taze yapraklar, } \\
\text { vazelinle merhem yapılır. }\end{array}$ & $\begin{array}{l}\text { Papillom (KK 43,77) } \\
\text { Öksürük giderici (KK 44) }\end{array}$ \\
\hline \multirow{3}{*}{ Lamiaceae } & Mentha sp. & $\begin{array}{l}\text { "Punk", "Pung" } \\
\text { Yarpuz } \\
\text { Kara nane }\end{array}$ & Yapraklar & Kaynatılıp suyu içirilir, sürülür. & $\begin{array}{l}\text { Yaralar (KK 16, 82), İshal (KK 27,63), Öksürük giderici (KK } \\
78)\end{array}$ \\
\hline & Teucrium polium & $\begin{array}{l}\text { "Meryemhort" } \\
\text { "Meyaro" } \\
\text { Mürvend otu } \\
\text { (Şekil 2) }\end{array}$ & $\begin{array}{l}\text { Toprak üstü kısım- } \\
\text { ları }\end{array}$ & Kaynatılıp suyu içirilir. & $\begin{array}{l}\text { Sarılık (KK 15) } \\
\text { Sancı giderici (KK 61,80) İç parazit (KK46), Kabızlık (KK 12) }\end{array}$ \\
\hline & Thymus sp. & Kekik & $\begin{array}{l}\text { Toprak üstü kısım- } \\
\text { ları }\end{array}$ & Suyu içirilir. & Kanatılılarda bağışıklık güçlendirici (KK 75) \\
\hline \multirow[b]{2}{*}{ Liliaceae } & Allium sativum. & $\begin{array}{l}\text { "Sir" } \\
\text { Sarımsak }\end{array}$ & Toprak altı gövdesi & $\begin{array}{l}\text { Ezilerek sürülür. } \\
\text { Yoğurtla, tuzla karıştırılıp ya } \\
\text { da sade yedirilir. } \\
\text { Hayvanların bulunduğu or- } \\
\text { tamda yakılır. } \\
\text { Limon suyu ile ezilerek. }\end{array}$ & $\begin{array}{l}\text { "Tebek" Şap hastalığı (KK 27), Uyuz (KK1, 30,38), Mantar } \\
\text { (KK1, 40,69,78), İshal (KK 57, 69,71), İç parazit (KK5), "Ze- } \\
\text { rik, Zerika Reş" Theileria (KK 20,74), Dış parazit (KK } \\
\text { 8,12,23,32,62,63,71,76) Sülük (KK 15), Zehirlenme (KK } \\
\text { 35,68), Nokra (KK 38), Kanatlılarda bağışıklık güçlendirici } \\
\text { (KK 75) }\end{array}$ \\
\hline & Allium cepa & Soğan & Toprak altı gövdesi & $\begin{array}{l}\text { Pişirilerek, közlenerek, ezile- } \\
\text { rek. } \\
\text { Pişirilip, yeşil sabunla karıştırı- } \\
\text { lır, apseye bağlanır. } \\
\text { Pişirilip yedirilir. } \\
\text { Yağda pişirilip, hayvanın ute- } \\
\text { rusuna yerleştirilir. } \\
\text { Yedirilir. }\end{array}$ & $\begin{array}{l}\text { Yaralar (KK 28,36,40,42,46,51,72,78 } \\
\text { Apse (KK 22, 23,29,32,50,76) } \\
\text { Öksürük (KK 23 } \\
\text { Eşin düşmemesinde (KK52,59) } \\
\text { Dış parazit (KK 8) } \\
\text { İştahsızlık (KK 67) } \\
\text { Arı sokması (KK 60) }\end{array}$ \\
\hline Lythraceae & Lawsonia inermis & Kına & Yapraklar & $\begin{array}{l}\text { Toz kına sulandırılıp içirilir. } \\
\text { Tuz ile karıştırılıp bölgeye sü- } \\
\text { rülür. }\end{array}$ & $\begin{array}{l}\text { Şişkinlik (KK1), Mantar (KK37,61) } \\
\text { Katarak (KK 13,20,28,51,57,80). }\end{array}$ \\
\hline \multirow[t]{2}{*}{ Magnoliidae } & Andrachne sp. & $\begin{array}{l}\text { Siğil otu } \\
\text { "Giya Baluka" }\end{array}$ & $\begin{array}{l}\text { Toprak üstü kısım- } \\
\text { ları }\end{array}$ & $\begin{array}{l}\text { Yedirilir. } \\
\text { Kaynatılır suyu içirilir. }\end{array}$ & Papillom (KK 13,30) \\
\hline & Crepis sp. & "Şirok" & Çiçekler & Kaynatılıp suyu içirilir. & Sarılık (KK 3) \\
\hline \multirow[t]{3}{*}{ Malvaceae } & Malva neglecta & $\begin{array}{l}\text { "Dolik" "Tolik" } \\
\text { "Dolık" “Tolık" } \\
\text { "Tollik" (Şekil } \\
\text { 3) Ebegömeci }\end{array}$ & Yapraklar & $\begin{array}{l}\text { Ezilip yaraya bağlanır, yaprak- } \\
\text { lar sarılır. } \\
\text { Haşlanarak çıkık olan bölgeye } \\
\text { sarılır. }\end{array}$ & $\begin{array}{l}\text { Yaralar (KK 19, 54,59,65) } \\
\text { Kalça Çıkığı (KK 72) }\end{array}$ \\
\hline & Alcea sp. & $\begin{array}{l}\text { "Hiro" “Hero" } \\
\text { Hatmi }\end{array}$ & Çiçekleri & $\begin{array}{l}\text { Ezilip bağlanır. } \\
\text { Su veya sütle kaynatılıp içirilir. } \\
\text { Beyaz çiçekli hiro kaynatılıp } \\
\text { suyu içirilir. }\end{array}$ & $\begin{array}{l}\text { Yaralar (KK 23,38), İshal (KK 21-23,35,38),Tuz zehirlenmesi } \\
\text { (KK 19), Eşin düşmemesinde (KK14,19,63) }\end{array}$ \\
\hline & $\begin{array}{l}\text { Hibiscus esculen- } \\
\text { tus }\end{array}$ & Bamya & Tohum & $\begin{array}{l}\text { Ezilip apseye sarılır. } \\
\text { Yedirilir. Haşlanıp sulu yediri- } \\
\text { lir. }\end{array}$ & Apse $(76,81)$, Eşin düşmemesinde (KK 81), Kabızlık (KK73) \\
\hline \multirow[t]{2}{*}{ Moraceae } & Morus sp. & Dut & $\begin{array}{l}\text { Pekmezi, Meyveleri } \\
\text { Kurusu, } \\
\text { Yapraklar }\end{array}$ & $\begin{array}{l}\text { Dut yaprağı apseye sarılır } \\
\text { Arpa unu pekmez ile karıştırılır } \\
\text { hamur yapılıp apseye veya kı- } \\
\text { rığa bağlanır. } \\
\text { Sulandırılıp içirilir. } \\
\text { Meyveleri yedirilir. }\end{array}$ & $\begin{array}{l}\text { Apse }(15,43,78) \text { Sarılık (KK1,41,50,68,76), İshal (KK50,76), } \\
\text { Sancı giderici (KK 7,32)“Zerik, Zerika Reş” Theileria (KK7, } \\
\text { 42,47,50,56,76). Eşin düşmemesinde ve doğum sonrası } \\
\text { sancılarında (KK7,17,33,49,66,67), Kırık (KK 78), İştahsızlık } \\
\text { (KK 25) }\end{array}$ \\
\hline & Ficus carica & İncir & Yapraklar & Kaynatılıp suyu sürülür. & Uyuz (KK 52) \\
\hline Oleaceae & $\begin{array}{l}\text { Olea } \\
\text { europaea }\end{array}$ & Zeytin & $\begin{array}{l}\text { Meyveleri, } \\
\text { Yağı }\end{array}$ & $\begin{array}{l}\text { Ekmek hamurunun içine zey- } \\
\text { tin konur, apseye bağlanır. } \\
\text { Zeytinyağı içirilir. } \\
\text { Sürülür. }\end{array}$ & $\begin{array}{l}\text { Apse (58) } \\
\text { Şişkinlik (KK5,18,27,33,38,42,47,68,70) } \\
\text { Uyuz (KK30) } \\
\text { Mastitis ve meme şişkinliğinde (KK15,27,28,32,47). } \\
\text { Papillom (KK 47), Sancı giderici (KK 47), Kabızlık (KK } \\
\text { 15,33,40,58), Abomasum deplasmanı (KK47) }\end{array}$ \\
\hline Papaveraceae & Papaver rhoeas & $\begin{array}{l}\text { "Edorak" } \\
\text { "Adorak" } \\
\text { Gelincik }\end{array}$ & Çiçek & Ezilip bağlanır. & Yaralar (KK 50,56) \\
\hline Piperaceae & Piper nigrum & Karabiber & Meyveleri & $\begin{array}{l}\text { Kaynatılır suyu içirilir. } \\
\text { Yeme katılıp yedirilir. }\end{array}$ & $\begin{array}{l}\text { Öksürük (KK 76) } \\
\text { Güvercinlerde döl verimi artırıcı (KK 75) }\end{array}$ \\
\hline $\begin{array}{l}\text { Plantagina- } \\
\text { ceae }\end{array}$ & Plantago sp. & $\begin{array}{l}\text { "Pelheves" } \\
\text { Sinir otu }\end{array}$ & Yapraklar & Yapraklar sarılır. & Yaralar (KK 57,65) \\
\hline
\end{tabular}




\section{TABLO 2'NIN DEVAMI}

Familya Latince tür Yöresel ad Buğday

Toprak üstü kısımlar

Poaceae

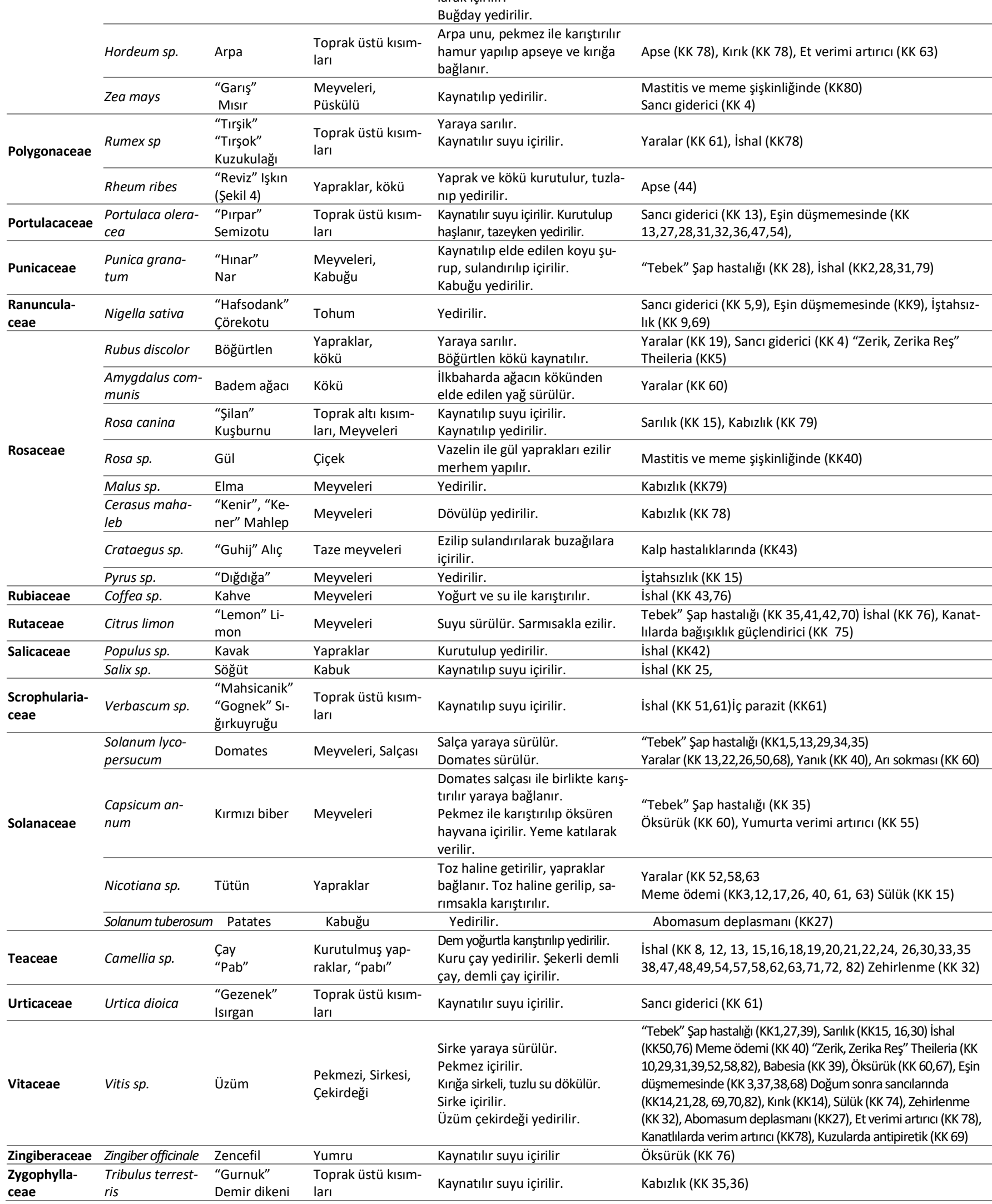

\section{Kullanma şekli}

Un, tuz veya şeker suyla karıştırıla-

rak hamur yapilır, apseye sarılır.

Bulgur pişirilir, tereyağı ile hamur

haline getirilip apseye bağlanır.

Un -yumurta- ve su karıştırılır, hamur sarılır.

Un, tuz, seker karısımı sulandır -

Mastitis ve meme şişkinliğinde (KK17,58)

Doğum sonrası sancılarında (KK 15,18,20,41)

Eşin düşmemesinde (KK 18,34,41), Kırık (KK47)

\section{Kullanım amacı}

pse $(40,58,74)$ Sarılık (KK11)
Arpa unu, pekmez ile karıştırılı

hamur yapılıp apseye ve kırığ

Kaynatılıp yedirilir.

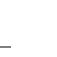




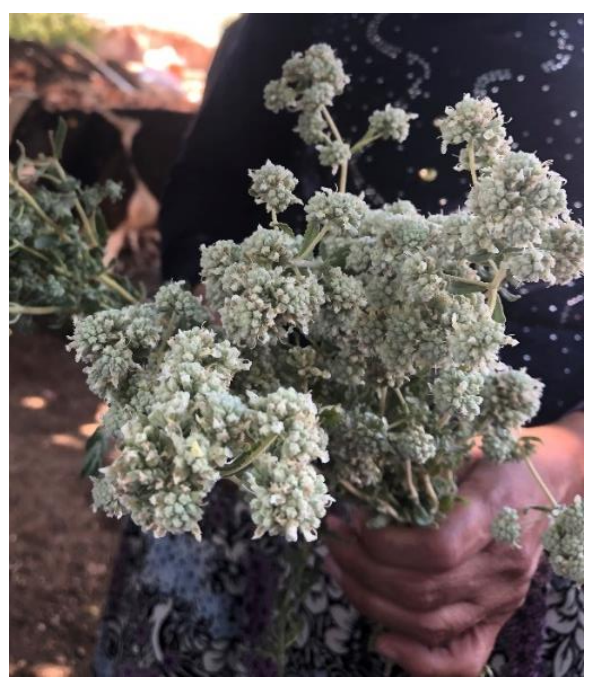

Şekil 2. "Meryemhort", "Meyaro" (Teucrium polium), Hani/DIYARBAKIR

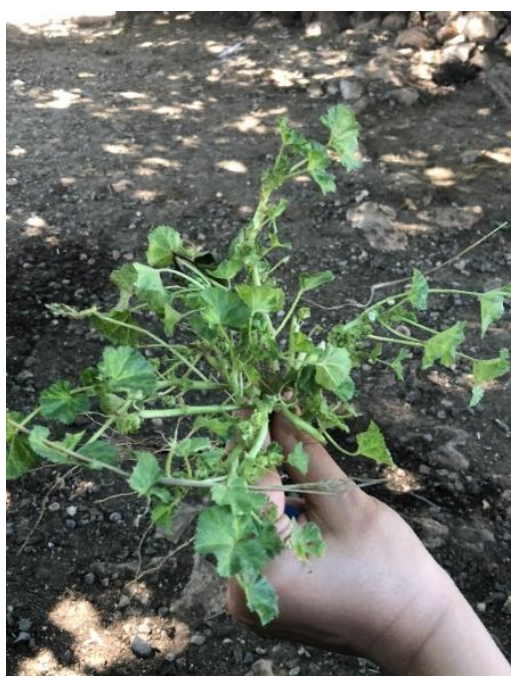

Şekil 3. "Dolik", "Tolik", "Tollik”, "Dolık”, "Tolı", (Malva neglecta) Hani/DiYARBAKIR

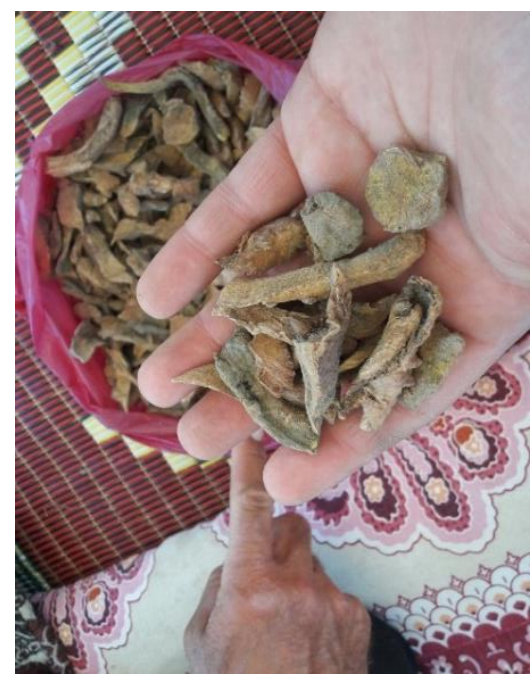

Şekil 4. "Reviz", kurutulmuş "Işkın” (Rheum ribes) kökü, Yukarı Eğin/ DiYARBAKIR

\section{TARTIŞMA VE SONUÇ}

Diyarbakır ve çevresinde yapılan bu araştırma sonucunda yörede; 75 bitkinin hayvan hastalıkları ve yetiştiriciliğinde kullanıldığı tespit edilmiştir. Yörede en yaygın olarak Rosaceae ( 8 bitki), Asteraceae ( 7 bitki) ve Solanaceae ( 4 bitki) familyaları kullanılmakla birlikte, toplam 43 farklı familyaya ait bitkinin kullanımı kayıt altına alınmıştır. Diyarbakır'da tıbbi amaçlı kullanılan bitkiler üzerine yapılan bir yüksek lisans tezinde 39 familyaya ait 66 bitkinin (Cucurbitaceae 6, Umbelliferae 5, Liliaceae ve Rosaceae 4'er bitki) halk hekimliğinde kullanımı bildirilmiştir (14). Yörede yapılan bu çalışmalarda insan ve hayvan hastalıklarının tedavisinde ortak olarak en fazla kulIanılan familyanın Rosaceae olduğu; ayrıca tıbbi amaçlı kullanımı saptanan bitkilerden on dokuzunun, hayvan hastalıklarında farklı tedavilerde kullanıldığı, sekizinin ise ("Batof" - sarılık, "Guruz" ve "Pelheves"- yara, "Kırmızı biber" ve "Papatya" - öksürük kesici, "Gal”, "Meşe palamudu" ve "Sumak" - ishal) kullanımlarının tıbbi ve veteriner hekimliği folklorunda örtüştüğü ve aynı hastalıklarda kullanılmaya devam edildiği görüldü. Değer'in yüksek lisans tezini yaptığı 1985 yılından bu yana yörede, aradan geçen zamana ve teknolojik gelişmelerle müstahzar ilaçların artışına rağmen, günümüzde hala insanların kendi hastalıkları için kullandığı bitkileri hayvanları için de kullanmaya devam ettikleri ve geleneksel uygulamalardan vazgeçmedikleri söylenebilir.

Veteriner hekimliği ile ilgili önceki folklorik çalışmalarda (15-35) belirtilmeyen "Köksor" (Amaranthus sp), "Sımmo" (Chrysophthalmum montanum), "Dığdığa” (Pyrus sp.), "Halundor" (Onopordum sp.), "Nerbendık" (Scorzonera latifolia), "Gurnık" (Xanthium sp.), "Tali" (Lactuca serriola) ve "Şirok"un (Crepis sp.) hayvan hastalıklarının tedavisi ve yetiştiricilikte kullanımları ilk kez bu çalışma ile saptandı. Ancak, Bingöl, Elazı̆̆, Mardin, Van gibi Anadolu'nun çeşitli illerinde halk hekimliğinde "Köksor"un ishalde $(36,37)$, "Sımmo"nun yaralarda (38), "Nerbendık"ın (39) ve "Gurnık"in sancılarda $(36,40,41)$ hayvan hastalıklarının tedavisindekine benzer kullanımları olduğu belirlendi. İnsanların farklı yörelerde halk hekimliğinde kullandıkları bitkilerin Diyarbakır'da hayvan hastalıklarının tedavisinde kullanımı, sözü edilen bitkilerin benzer florada yetişmelerinden kaynaklanabileceği gibi, folklorik bilgilerin toplumlar arasında aktarılarak hayvanlarda da kullanılmış olabileceğini akla getirmektedir.

Yörede, yarada "Pelheves" (4,28,33,35), "Dolik" (4), “Gürüz" (4,33), "Tırşik" (4), "Böğürtlen yaprağı" (4), "Ardıç katranı" (34), "Meşe" (4), "Soğan" (4,10,32,34), "Sumak" (4,10, 21,28, 33,34), "Hiro" $(19,33,35)$; eşin düşmemesinde "Kızın" (4), "Hiro" (35), "Pırpar" (4, 10), "Buğday" (4, 31) "Dut" (4,28), "Soğan" (4,10,12,28,31), "Üzüm $(4,31)$; ishalde "Tırşik" (4), "Çay $(4,10,21,28,32,35)$ "Dut" (4,21), "Limon" (10), "Meşe" (10,21), "Papatya" (4), "Sarımsak" (4,22,35), "Söğüt yaprağı" (28), "Sumak" $(4,19,21)$; verim artırıcı olarak "Arpa" (4,18,19,26), "Kırmızı biber" (4); kabızlık "Sinameki" (28) “Ayçiçeği yağı” (10,28,35), "Zeytinyağı" (10,22,23,35); meme hastalıklarında "Gül yağı" $(10,16,27)$; uyuzda "Meşe" $(10,29)$, "Sarımsak" $(10,28,29)$, "Zeytinyağı" $(17,19,23,29)$; zehirlenmede "Sarmısak" (20-22,25) kullanıldığı belirlendi. Bu bitkilerden bir kısmının veteriner hekimliği folkloru çalışmalarında $(4,10,21-23,29,31-35)$ benzer hastalık ve durumlarda kullanıldığı, bir kısmının da köklerinin -dokuzuncu yüzyıla- baytarnamelere $(16,18,19,27)$ kadar uzandığı söylenebilir.

Dünyanın çeşitli ülkelerinde (Hırvatistan, İtalya, Nepal, Cezayir, Romanya, Pakistan, Hindistan vs.) yapılan veteriner hekimliği folkloruna ait çalışmalarda (42-55) hayvan hastalıklarında kullanılan bitkiler incelendiğinde, Diyarbakır yöresiyle örtüşen bazı sonuçlara ulaşıldı. Yara tedavisinde "Ardıç" (Juniperus oxycedrus) (42), "Meşe" (Quercisus sp.) (43), "Üzüm" (Vitis sp) (43,44), "Mısır" (Zea may) (43), "Pelheves" (Plantago sp.) (43,45,53), "Böğürtlen" (Rubus sp.) (43), "Nar" (Punica granulatum) (46), "Dolik" (Malva sp.) $(47,48)$ "Soğan" (Allium cepa) (49,50), "Mahsicanik" (Verbascum sp.) (43); gastroeintestinal hastalıklarda (ishal, sancı, hazımsızlık vb.) "Meşe" (Quercisus sp.) (43,51), "Sarımsak" (Allium sativum) (43,50), "Üzüm” (Vitis sp) (43), “Mısır (Zea may) (43), 
"Söğüt" (Salix sp.) (43), "Mahsicanik" (Verbascum sp) (43), "Dut" (Morus sp.) (45), "Meryemhort" (Teucrium polium) (46), "Nar" (Punica granulatum) (52), "Nane" (Mentha sp) (52), "Tırşik" (Rumex sp) (48,51); şap hastalığında "Sumak" (Rhus sp) (55); jinekolojik problemlerde "Mısır" (Zea may) (43); iç ve dış parazit tedavisinde "Sarımsak" (Allium sativum) (44-47,49,51,54,56), "Tütün" (Nicotiana sp.) (43,56), "Meşe” (Quercus sp.) (51), "Zeytinyăgı" (Olea europea) (44,54), "Üzüm (Vitis sp.) (43-44), "Soğan" (Allium cepa) (50,54); zehirlenme tedavisinde "Zeytinyağı" (Olea europea) (45), "Sarımsak" (Allium sativum) (50); şap hastalığında "Sımak" (Rhus sp.) (55), "Kırmızı biber" (Capsinum annum) (56), "Lemon" (Citrus limon) (56); öksürükte "Zencefil (Zingiber officinale) (52,53), "Papatya" (Anthemis sp.) (44), "Karabiber" (Piper nigrum) (50); meme ödemi giderici "Üzüm” (Vitis $s p)$ (45); sarılıkta "Sarımsak" (Allium sativum) (46); kanatlılarda yumurta verimi artırıcı "Kırmızı biber" (Capsinum annum) (43) kullanımı saptandı. Çok eski tarihlerden beri ticaret yolları sadece ticari malları değil farklı toplumların kültürel, sanatsal, bilimsel ürünlerini de taşımıştır (57). Doğu ve batıyı birleştiren bir coğrafyada, uzak bölgeleri denizlere ve liman şehirlerine bağlayan ana ulaşım yollarının kavşak noktasında bulunan Diyarbakır'da (58), hayvan hastalıklarında kullanılan bitkilerin dünyanın farklı ülkelerinde de aynı hastalıklarda kullanılıyor olması, çeşitli toplumlarda kullanılan bitkilere ait folklorik bilgilerin ticaret esnasında tüccarlar tarafından farklı ülkelere taşınmış olabileceğini düşündürmektedir.

Sonuç olarak, Diyarbakır yöresinde yapılan bu çalışma ile bitkilerin, hayvan hastalık ve yetiştiriciliğinde kullanım amaç, yöntem ve şekillerinin kayıt altına alınmasının hem kültürel mirasın korunması hem de yeni ilaç araştırmalarına kaynak oluşturabilme potansiyeli açısından önem taşıdığı söylenebilir.

\section{TEŞEKKÜR}

Saha çalışmaları boyunca misafirperverliklerinden dolayı Diyarbakır halkına, Veteriner Hekim Mehmet Ölçay, Veteriner Hekim Bedirhan Üstün ve Emekli Sağlık Memuru Sabri Aygün'e, bitkilerin adlandırılmasında yardımlarından dolayı Fırat Üniversitesi Fen Fakültesi, Biyoloji Bölümü Öğretim Üyesi Doç. Dr. Gülden Doğan'a teşekkür ederim.

\section{KAYNAKLAR}

1. Karasszon D. (1988). A Concise of History of Veterinary Medicine. (Translated by E. Farkas). Akademiai Kiado, Budapest.

2. Öztürk R. (2002). Türkiye'de Veteriner Illaç Sanayiinin Tarihsel Gelişimi. Doktora Tezi. Ankara Üniversitesi Sağlık Bilimleri Enstitüsü, s. 1-11, Ankara.

3. Khattak NS, Nouroz F, Rahman IU, Noreen S. (2015). Ethno veterinary uses of medicinal plants of district Karak, Pakistan. J Ethnopharmacol. 171: 273-279.

4. Özen R, Doğan G. (2017). Elazığ Yöresinde Veteriner Hekimliği Folklorunda Kullanılan Bitkisel İlaç Ham Maddeleri. Lokman Hekim Derg.7(3):166-177.

5. Sezik E, Tabata M, Yeşilada E, Honda G, Goto K, Ikeshiro Y. (1991). Traditional medicine in Turkey. I. Folk medicine in Northeast Anatolia. J Ethnopharmacol. 35:191-196.
6. Nadiroğlu M, Behçet L, Çakılcıoğlu U. (2019). An Ethnobotanical Survey of Medicinal Plants in Karlıova (Bingöl-Turkey). Indian J Tradit Knowl. 18(1): 76-87.

7. Kızıl S, Tonçer Ö. (2014). Diyarbakır ve Çevresinden Doğadan Toplanarak Tüketilen Bitkiler, II. Tıbbi ve Aromatik Bitkiler Sempozyumu, 23-25 Eylül, Yalova-Türkiye.

8. Akan H, Bakır Sade Y. (2015). Kâhta (Adıyaman) Merkezi ve Narince Köyü'nün Etnobotanik Açıdan Araştırılması. BEÜ Fen Bilimleri Derg. 4(2): 219-248.

9. Yapıcı Ü, Hoşgören H, Saya, Ö. (2009). Kurtalan (Siirt) İlçesinin Etnobotanik Özellikleri. DÜ Ziya Gökalp Eğitim Fak Derg. (12): 191-196.

10. Yüksel E. (2012). Aşağı Fırat Havzasında Veteriner Hekimliği Folkloru Üzerine Araştırmalar. Doktora Tezi. Fırat Üniversitesi Sağlık Bilimleri Enstitüsü, s. 1-11,67-111, Elazığ.

11. Davis PH. (1965-1985). Flora of Turkey and the East Aegean Islands.Vol.1-9. Edinburgh Univ. Press, Edinburgh.

12. Baytop T. (1997). Türkçe Bitki Adları Sözlüğü. TTK Basımevi, Ankara.

13. Fırat M. (2013). Kürtçe Bitki Adları Sözlüğü. Sitav Yayınevi, Van.

14. Değer M. (1985). Diyarbakır Yöresi Halk İlaçları ve Tedavi Yöntemleri. Yüksek Lisans Tezi. İstanbul Üniversitesi Sağlık Bilimleri Enstitüsü, s.14-40, İstanbul.

15. Erk N. (1955). XVI'ıncı Asır Veteriner Hekimliği ve Bu Asra Ait Eserler. Yeni Desen Matbaası, Ankara.

16. Erk N. (1959). İslam Medeniyeti Çağında Veteriner Tababette Gelişmeler ve Naseri. Yeni Matbaa, Ankara.

17. Erk N. (1961). "Tuhfetülfarisin Fi Ahval-i Huyul El-Mücahaddin" Adlı Kitabın Illimler Tarihi Yönünden İncelenmesi. DTCF Dergisi. 17(4): 495-511.

18. Erk N. (1961). A Study of the Veterinary Section of ibn AlAwwam's "Kitab al-Falaha". Ankara Üniv Vet Fak Derg. 8(3): 241-250.

19. Erk N. (1961). Dokuzuncu Yüzyıla Ait "Kitab Al -Hayl Val-Baytara" Üzerinde Bir İnceleme. Ankara Üniv Vet Fak Derg. 8(4): 367-386.

20. Erk N, Dinçer F. (1967). XV inci Ya da XVI ıncı Yüzyıla Ait Olduğu Sanılan Bir Baytarname Incelemesi. Ankara Üniv Vet Fak Derg.14(2): 117-139.

21.Dinçer F. (1967). Türk Folklorunda Veteriner Hekimliği Üzerine Araştırmalar. Ankara Üniversitesi Veteriner ve Ziraat Fakülteleri Basımevi, Ankara.

22.Doğanay S. (1982). Afyon Folklorunda Veteriner Hekimlik Araştırma ve Incelemeleri. II. Milletlerarası Türk Folklor Kongresi Bildirileri Kitabı Cilt 4. GÜ Basın Yayın Yüksekokul Basımevi, Ankara.

23. Arslan ES. (1998). Ege Bölgesi Folklorunda Veteriner Hekimliği ve Hayvancılık Üzerine Araştırmalar. Doktora Tezi. Ankara Üniversitesi Sağlık Bilimleri Enstitüsü, s. 12-68, Ankara.

24. Özen A. (1999). Milli Kütüphanedeki Yazma Baytarnameler Üzerinde Tarihsel İncelemeler. Doktora Tezi. Ankara Üniversitesi Sağılık Bilimleri Enstitüsü, s. 19-122, Ankara.

25. Yerlikaya H. (2002). Elazığ ve Çevresinde Hayvan Hastalıklarında Halk Hekimliği Üzerine Araştırmalar. Kafkas Univ Vet Fak Derg. 8(2): 131-138.

26. Özen A, Taşkın Ü. (2010). Baytarname-i Kenan Efendi. Bizim Büro Basımevi, Ankara.

27. Yiğit A. (2011) İlm-i Fürusiyet İsimli Baytarnamenin Veteriner Hekimliği Tarihi, At Yetiştiriciliği ve Hastalıklar Açısından 
Incelenmesi. Doktora Tezi. Selçuk Üniversitesi Sağıık Bilimleri Enstitüsü, s. 87-71, Konya.

28. Sinmez ÇÇ. (2011). Bozlak Kültüründe Folklorik Veteriner Hekimliği ve Hayvancılık Üzerine Araştırma. Doktora Tezi. Selçuk Üniversitesi Sağlık Bilimleri Enstitüsü, s. 21-70, Konya.

29. Yaşar A, Sinmez CÇ, Aslım G. (2015). İç Anadolu Bölgesi Konya Bölümü Folklorunda Ruminantların Paraziter Hastalıkları ve Tedavi Yöntemleri. Kafkas Univ Vet Fak Derg. 21(1): 1-7.

30. Avcı A, Özen R. (2016). Kara Hekim: Katran"ın Antalya Veteriner Hekimliği Folklorunda Hayvan Hastalıklarının Tedavisinde Kullanımı. F.Ü. Sağ Bil Vet Derg. 30(1): 39-44.

31. Sinmez ÇÇ, Yaşar A. (2016). Konya Bölümü Folklorik Veteriner Hekimliğinde Ruminantlarda Doğum Bilgisi ve Jinekoloji. Kafkas Univ Vet Fak Derg. 22(3): 409-415.

32. Sinmez ÇÇ, Aslım G. (2017). An Ethnoveterinary Remedies Used in the Treatment of Diseases of Aksaray Malaklısı Shepherd Dogs. Erciyes Üniv Vet Fak Derg. 14(3): 191-200.

33. Küçükaslan Ö. (2018). Diyarbakır Folklorunda Hayvanların Yara Tedavisinde Uygulanan Yöntemler, VI. Ulusal Veteriner Hekimliği Tarihi ve Mesleki Etik Sempozyumu, 4-6 Ekim, Elazığ-Türkiye.

34. Sinmez ÇÇ, Aslım G, Yaşar A. (2018). AnEthnoveterinary Studyon Plants Used in the Treatment of Dermatological Diseases in Central Anatolia, Turkey.J Complement Med Res. 8:71-84.

35. Kardaş C. (2019). Muş'ta Halk Veterinerliği ve Geleneksel Tedavi Yöntemleri. Ürün Yayınları, Ankara.

36. Polat R, Cakılcıoğlu U, Satıl F. (2013). Traditional Uses of Medicinal Plants in Solhan (Bingöl Turkey). J Ethnopharmacol. 148(3): 951-963.

37. Polat R. (2019). Ethnobotanical Study on Medicinal Plants in Bingöl (City Center) (Turkey). J Herb Med. 16: 1-11.

38. Arasan Ş. (2014). Savur (Mardin) Yöresinde Halk Hekimliğinde Kullanılan Bitkiler ve Kullanım Alanları. Yüksek Lisans Tezi. Yüzüncü Yıl Üniversitesi Fen Bilimleri Enstitüsü, s.40,224, Van.

39. Mükemre M. (2013). Konalga, Sırmalı, Dokuzdam Köyleri (Çatak-Van) ve Çevrelerinin Etnobotanik Özellikleri. Yüksek Lisans Tezi. Yüzüncü Yıl Üniversitesi Fen Bilimleri Enstitüsü, s.74, Van.

40. Türkoğlu i. (2000). Elazığ İlindeki Etnobotanik Değeri Olan Taksonların Araştııılması. Yüksek Lisans Tezi. Fırat Üniversitesi Fen Bilimleri Enstitüsü, s.42-43, Elazı̆g.

41. Olgun Ş. (2019). Arıcak (Elazığ) i̇lçesinin Etnobotanik Özellikleri. Yüksek Lisans Tezi. Bingöl Üniversitesi Fen Bilimleri Enstitüsü, s.53, Bingöl.

42. Bruni A, Ballero M, Pol, F. (1997). Quantitative Ethnopharmacological Study of the Campidano Valley and Urzulei District, Sardinia, Italy. J Ethnopharmacol. 57(2):97-124.

43. Viegi L, Pieroni A, Guarrera PM, Vangelisti R. (2003). A Review of Plants Used in Folk Veterinary Medicine in Italy as Basis for a Databank. J Ethnopharmacol. 89(2-3): 221-244.

44. Bullitta S, Re GA, Manunta MDI, Piluzza G. (2018). Traditional Knowledge About Plant, Animal, and Mineral-Based Remedies to Treat Cattle, Pigs, Horses, and Other Domestic Animals in the Mediterranean Island of Sardinia. J Ethnobiol Ethnomedicine. 14(1): 1-26.
45. Uncini Manganelli RE, Camangi F, Tomei PE. (2001). Curing Animals With Plants: Traditional Usage in Tuscany (Italy). J Ethnopharmacol. 78(2-3):171-191.

46. Miara MD, Bendif $H$, Ouabed A, et al. (2019) . Ethnoveterinary Remedies Used in the Algerian Steppe: Exploring the Relationship with Traditional Human Herbal Medicine. J Ethnopharmacol. 244: 112164.

47. Viegi L, Bioli A, Vangelisti R, Cela Renzoni G. (1999). Prima Indaginesulle Piante Utilizzate in Medicina Veterinaria Popolare in Alcune Localitàdell'alta Val di Cecina. Atti della Societ a Toscana di Scienze Naturali,Memorie Serie B. 106: 131-140.

48. Disler M, Ivemeyer S, Hamburger M, et al. (2014). Ethnoveterinary Herbal Remedies Used by Farmers in Four North-Eastern Swiss Cantons (St. Gallen, Thurgau, Appenzell Innerrhoden and Appenzell Ausserrhoden). J Ethnobiol Ethnomedicine. 10(1): 122.

49. Vučevat-Bajt V, Karlović M (1994). Traditional Methods for the Treatment of Animal Diseases in Croatia. Rev Sci Tech. 13:499512.

50. Sikarwar RLS, Tiwari AP. (2020). A Review of Plants Used in Ethnoveterinary Medicine in Central India. Indian Journal of Traditional Knowledge.I 19(3):617-634.

51. Bartha SG, Quave CL, Balogh L, Papp N. (2015). Ethnoveterinary Practices of Covasna County, Transylvania, Romania. J Ethnobiol Ethnomed. 11:35-57.

52. Deeba F, Muhammad G, Iqbal Z, Hussain I. (2009). Survey of Ethnoveterinary Practices Used for Different Ailments in Dairy Animals in Peri-Urban Areas of Faisalabad (Pakistan). Int J Agric Biol. 11(5):535-541

53. Bharati KA, Sharma BL. (2012). Plants Used as Ethnoveterinary Medicines in Sikkim Himalayas. Ethnobot Res Appl. 2012, 10:339-356.

54. Ali-Shtayeh Mohammed S, Jamous RM, Jamous RM. (2016). Traditional Arabic Palestinian Ethnoveterinary Practices in Animal Health Care: a Field Survey in the West Bank (Palestine). J Ethnopharmacol. 82:35-49.

55. Malla B, Chhetri R. (2012). Ethnoveterinary Practices of Some Plant Species by Ethnic People of Parbat District, Nepal. Kathmandu Uni J Sci Eng Tech. 8(1):44-50.

56. Bakare AG, Shah S, Bautista-Jimenez V, et al. (2020). Potential of Ethno-Veterinary Medicine in Animal Health Care Practices in the South Pacific Island Countries: A Review. Trop Anim Health Prod. 52:2193-2203.

57. Öztürk R. (2003). illk Çağda Bilim Göçü. Veteriner Hekimleri Derneği Dergisi.74(1-2):31-34.

58. T.C. Diyarbakır Valiliği. Diyarbakır Tarihi.

Erişim: http://diyarbakir.gov.tr/diyarbakir-tarihi. Erişim tarihi: 30.12.2020.

Sorumlu Yazar:
Rahşan ÖZEN
Fırat Üniversitesi Veteriner Fakültesi, VHT ve Deontoloji
Anabilim Dalı, Elaziğ, TÜRKIYE
E-posta: rahsanozen@hotmail.com

